\title{
Outcome of pregnancy in gestational diabetes as compared to overt diabetes
}

\author{
Chirag R. Banker, Latika R. Mehta*
}

Department of Obstetrics and Gynecology, GMERS Medical College and Hospital, Gandhinagar, Gujarat, India

Received: 20 November 2019

Accepted: 30 December 2019

*Correspondence:

Dr. Latika R. Mehta,

E-mail: drlatikamehta@gmail.com

Copyright: (C) the author(s), publisher and licensee Medip Academy. This is an open-access article distributed under the terms of the Creative Commons Attribution Non-Commercial License, which permits unrestricted non-commercial use, distribution, and reproduction in any medium, provided the original work is properly cited.

\section{ABSTRACT}

Background: Diabetes mellitus is a chronic metabolic disorder characterised by polyuria, polyphagia, polydipsia and glycosuria. Diabetes in pregnancy can be defined as pregestational (pre-existing) diabetes or gestational diabetes have type 1 (T1DM) or type 2 (T2DM) diabetes mellitus. Present study was carried to compare the maternal and perinatal outcome of overt diabetes mellitus as compared to gestational diabetes mellitus (PGDM) with that of gestational diabetes (GDM).

Methods: An observational study was conducted at obstetrics and gynaecology department of a tertiary care center from July 2010 to October 2012 among 23 diabetic women. Seven of them were cases of overt diabetes while 16 were diagnosed during pregnancy. Maternal and fetal outcome were studied. All patients were followed from time of admission to discharge from hospital.

Results: mean age of the participants were $26.71 \pm 4.89$ in overt diabetes as compared to $27.56 \pm 4.41$ among gestational diabetes. Illiteracy, low socio-economic status, rural residence, family history of diabetes was also high in overt diabetes mellitus as compared to GDM but none of them was statistically significant $(\mathrm{P}<0.05)$. Intrauterine fetal death was more among GDM (37.5\%) as compared to overt diabetes (28.57\%). Prematurity and LBW were also high in overt diabetes as compared to GDM but none of them were statistically significant. Oligohydramnios, polyhydramnios and premature rupture of membrane were higher in gestational diabetes mellitus as compared to overt diabetes among women. Rate of LSCS were higher in gestational diabetes.

Conclusions: Diabetes whether over or gestational is responsible for the poor outcome of the pregnancy so tight control is needed.

Keywords: Gestational diabetes, Overt diabetes, Perinatal outcome

\section{INTRODUCTION}

Diabetes mellitus is a chronic metabolic disorder characterised by polyuria, polyphagia, polydipsia and glycosuria. Diabetes in pregnancy can be defined as pregestational (pre-existing) diabetes or gestational diabetes have type 1 (T1DM) or type 2 (T2DM) diabetes mellitus. Less common types of pregestational diabetes include monogenetic and mitochondrial disorders, and secondary causes such as cystic fibrosis. GDM, defined as glucose intolerance occurring during or first recognised in pregnancy, affects $2-5 \%$ of today's antenatal population. ${ }^{1}$ Diabetes is a major public health problem in India with prevalence rates reported to be between $4.6 \%$ and $14 \%$ in urban areas, and $1.7 \%$ and $13.2 \%$ in rural areas.

India has an estimated 62 million people with type-2 diabetes mellitus (DM); this number is expected to go up to 79.4 million by $2025 .{ }^{2}$ It is estimated that about 4 
million women are affected by GDM in India, at any given time point. ${ }^{3}$

The risk factors for gestational diabetes mellitus are age > 30 years, family history of diabetes mellitus, obesity, history of macrosomia, glycosuria, previous unexplained neonatal death, unexplained recurrent abortion, Previous congenital malformations, history of hydramnios, history of stillbirth, history of gestational hypertension and history of pre-eclampsia. Teenagers of mother who drank alcohol were less likely to have gestational diabetes mellitus. ${ }^{4,5}$

Gestational diabetes mellitus is associated with increased risk for mother and foetus during the pregnancy and birth and in later life. Maternal complications are preeclampsia and caesarean delivery. Foetal complications are shoulder dystocia, birth injuries, neonatal hyperbilirubinemia, hypoglycaemia and respiratory distress syndrome. For the mother, gestational diabetes mellitus is a very strong risk factor for the development of type 2 diabetes mellitus, metabolic syndrome and cardiovascular disease later in life. ${ }^{8}$ Gestational diabetes can lead to miscarriage, premature delivery, congenital malformations, altered fetal growth, unexplained fetal demise, hydroamnios and other neonatal complications. Uncontrolled diabetes mellitus in pregnancy leads to preeclampsia, diabetic ketoacidosis, diabetic nephropathy, diabetic retinopathy, neuropathy in mothers. Macrosomia is one of the major effects of GDM. ${ }^{6-8}$

It is a known fact that diabetes may have negative effects on pregnancy if not taken care of. Existing diabetes before pregnancy (pregestational diabetes mellitus, PDM) may have negative effects on the embryonic development while gestational diabetes mellitus (GDM) that occurs during late stages of pregnancy may affect the growth and maturation of the fetus. The common feature of PDM and GDM is abnormal high maternal blood glucose levels stated as hyperglycaemia. Women with PDM have 2-5 times increased risk of delivering malformed babies. The PDM women with early onset of diabetes, longest diabetes duration, with pregnancy complications and increased glycosylated haemoglobin levels have the highest risk of producing growth retarded and malformed babies. ${ }^{9,10}$

Gestational diabetes leads to macrosomic infant (birth weight exceeds 4500 gram) due to excessive fat deposition on shoulders and trunk which predisposes them to shoulder dystocia or caesarean delivery. The HAPO study demonstrate that maternal hyperglycaemia even at a level below that diagnostic of DM is associated with increased birth weight and macrosomia. An increase in morbidity during pregnancy with a likelihood of developing diabetes in future is associated with maternal hyperglycaemia. This also has a direct impact on the developing foetal pancreas and remains a risk factor for developing DM in future. ${ }^{11,12}$ The present study was aimed to know the feto-maternal outcome of pregestational and gestational diabetes.

\section{METHODS}

Study type, study duration and study setting: An observational study was conducted at obstetrics and gynaecology department of a tertiary care center from July 2010 to October 2012.

All the patients who had pregnancy aged 18 to 45 years with diabetes (overt or gestational) were included in this study. All cases, registered or emergency, were included in study.

All eligible participants were selected purposively who came at hospital during the study period. Twenty-three participants were examined.

\section{Diagnosis of diabetes during pregnancy}

\section{Overt diabetes}

Women who were known to have diabetes before pregnancy are included in pre-gestational or overt diabetes. Women with random plasma glucose level greater than $200 \mathrm{mg} / \mathrm{dL}$ plus classic signs and symptoms such as polydipsia, polyuria and unexplained weight loss or a fasting glucose exceeding $125 \mathrm{mg} / \mathrm{dL}$ are considered to have overt diabetes. ${ }^{13}$

\section{Gestational diabetes}

It is defined as carbohydrate intolerance of variable severity with onset or first recognition during pregnancy. According to this definition some women classified as GDM may have previously unrecognized overt diabetes.

\section{Data collection}

After getting ethical approval from ethical committee, the study was started. Participants were acquiring purposively. All the participants were informed about the nature and purpose of the study and they were enrolled in the study if they were agree to participate, after signing informed consent form. History and examination were carried out in all participants were. During their stay at hospital, routine blood investigations were carried out like CBC, RFT, LFT. HbA1C was measured to get idea about blood glucose control over past 3 months. Acetone for complications like ketoacidosis. RBS measured 6 hourly. Insulin requirement during antepartum, intrapartum and post-partum period was observed. Ultrasound examination was performed for foetal growth, amniotic fluid volume, foetal cardiac activity and presence of any foetal malformation. Mode of delivery vaginal or LSCS was studied. At last maternal and foetal outcome were studied. All patients were followed from time of admission to discharge from hospital. 


\section{Inclusion criteria}

- Pregnant lady met diagnosis criteria for overt diabetes and gestational diabetes diagnosis criteria given above

- Pregnant lady who was ready to give consent.

\section{Exclusion criteria}

- Pregnant lady who did not met diagnosis criteria for overt diabetes and gestational diabetes

- Pregnant lady who wasn't ready to give consent.

\section{Statistical analysis}

Data were entered and analysed with epi info 7. Continuous variables were expressed as mean and standard deviation and categorical variables were expressed as percentages. Chi square and t-test were applied accordingly.

\section{RESULTS}

Table 1 shows descriptive characteristics of the study participants. Mean age was higher among gestational diabetes mellitus as compared to overt diabetes mellitus but it was not statistically significant. Illiteracy, low socio-economic status, rural residence, family history of diabetes was also high in overt diabetes mellitus as compared to GDM but none of them was statistically significant $(\mathrm{P}<0.05)$. Mean blood sugar was higher in gestational diabetes mellitus while glycosylated hemoglobin was higher in overt diabetes but not statistically significant.

Table 1: Descriptive characteristics of the study participants $(n=23)$.

\begin{tabular}{|llll|}
\hline Variables & Overt diabetes $(\mathbf{n}=\mathbf{7})$ & GDM $(\mathbf{n}=\mathbf{1 6})$ & P-value \\
\hline Age & $26.71 \pm 4.89$ & $27.56 \pm 4.41$ & 0.685 \\
\hline Height & $162.0 \pm 6.35$ & $160.56 \pm 6.36$ & 0.623 \\
\hline Weight & $69.0 \pm 18.66$ & $62.81 \pm 7.64$ & 0.264 \\
\hline BMI & $26.09 \pm 5.69$ & $24.41 \pm 2.75$ & 0.344 \\
\hline Pulse & $86.57 \pm 3.60$ & $89.87 \pm 14.96$ & 0.575 \\
\hline Hemoglobin & $11.86 \pm 1.69$ & $11.38 \pm 2.08$ & 0.602 \\
\hline RBS & $132.86 \pm 76.65$ & $142.19 \pm 101.37$ & 0.83 \\
\hline HbA1C & $7.54 \pm 1.30$ & $7.31 \pm 1.37$ & 0.711 \\
\hline Fetal weight & $2.55 \pm 0.73$ & $2.58 \pm 0.78$ & 0.937 \\
\hline Rural residence & $01(14.29 \%)$ & $02(12.5 \%)$ & 1.00 \\
\hline Illiteracy & $03(42.85 \%)$ & $05(31.25 \%)$ & 0.95 \\
\hline Low SES & $07(100 \%)$ & $14(87.5 \%)$ & 1.0 \\
\hline Multigravida $>>2)$ & $04(57.14)$ & $06(37.5 \%)$ & 0.67 \\
\hline Family history of diabetes & $02(28.57)$ & $04(25 \%)$ & 1.0 \\
\hline
\end{tabular}

Table: 2 Maternal complications among study participants $(n=23)$.

\begin{tabular}{|lllll|}
\hline Variables & $\begin{array}{l}\text { Overt diabetes }(\mathbf{n}=\mathbf{7}) \\
\mathbf{n}(\%)\end{array}$ & $\begin{array}{l}\text { Gestational diabetes }(\mathbf{n}=\mathbf{2 3}) \\
\mathbf{n}(\%)\end{array}$ & OR & P-value \\
\hline Oligohydramnios & $1(14.29)$ & $4(25)$ & 0.5 & 0.98 \\
\hline Polyhydramnios & $1(14.29)$ & $3(18.75)$ & 0.72 & 1 \\
\hline PIH/preeclampsia/eclampsia & $1(14.29)$ & $2(12.5)$ & 1.17 & 1 \\
\hline PROM & $1(14.29)$ & $4(25)$ & 0.5 & 0.98 \\
\hline DKA & $1(14.29)$ & $0(0.0)$ & NA & 0.3 \\
\hline LSCS & $3(42.86)$ & $10(62.5)$ & 0.45 & 0.65 \\
\hline Wound gap & $0(0.0)$ & $1(6.25)$ & 0 & 1 \\
\hline Septicaemia & $1(14.29)$ & $0(0.0)$ & NA & 0.3 \\
\hline Death of mother & $0(0.0)$ & $1(6.25)$ & 0 & 1
\end{tabular}

According to Table 2, oligohydramnios, polyhydramnios and premature rupture of membrane were higher in gestational diabetes mellitus as compared to overt diabetes among women. Rate of LSCS were higher in gestational diabetes. One women were having DKA among overt diabetes and one woman died among gestational diabetes mellitus. Intrauterine fetal death was more among GDM $(37.5 \%)$ as compared to overt diabetes $(28.57 \%)$.

Prematurity and LBW were also high in overt diabetes as compared to GDM but none of them were statistically significant (Table 3). 
Table 3: Outcome of baby among study participants $(n=23)$.

\begin{tabular}{|lllll|}
\hline Variables & $\begin{array}{l}\text { Overt diabetes }(\mathbf{n}=\mathbf{7}) \\
\mathbf{n}(\boldsymbol{\%})\end{array}$ & $\begin{array}{l}\text { Gestational diabetes }(\mathbf{n}=\mathbf{2 3}) \\
\mathbf{n}(\boldsymbol{\%})\end{array}$ & OR & P-value \\
\hline IUFD & $2(28.57)$ & $6(37.5)$ & 0.67 & 1 \\
\hline Prematurity & $228.57)$ & $2(12.5)$ & 2.8 & 0.73 \\
\hline LBW & $3(42.86)$ & $6(37.5)$ & 1.25 & 1 \\
\hline Congenital malformations & $1(14.29)$ & $1(6.25)$ & 2.5 & 1 \\
\hline
\end{tabular}

\section{DISCUSSION}

The present study examined the difference in pregnancy outcomes between women with GDM and ODM. During the period from July 2010 to October 2012, 23 patients were admitted at our institute with diabetes in pregnancy. It includes both gestational diabetes and overt diabetes.

In this study, there was no significant difference between PGDM and GDM regarding mean age of the study subjects. In a study of Clausen et al, shows that increasing age of the patients of GDM had been described as a risk factor for pregnancy complication maternal age was higher in overt diabetes than that of GDM in the study of Wahabi et al. ${ }^{14,15}$ In this study $56.43 \%$ patients were delivered by caesarean section. Rest were delivered vaginally. Most common indications for caesarean section were big baby or previous caesarean section. According to Jindal et al, cesarean section was required in $44 \%$ patients. LSCS was also higher among gestational diabetes as compared to overt diabetes in our study while previous studies show caesarean section was more frequently needed in overt diabetes as compared to gestational diabetes. ${ }^{16}$ This may be due to higher sample in GDM.

In our study, one patient in the study group expired, which accounted for $4.35 \%$ mortality. Cause of death in this patient was diabetic ketoacidosis + septicaemia. According to Buckshee et al, maternal mortality is 10 times higher in GDM patients. ${ }^{17}$ In present study, oligohydramnios, polyhydramnios and premature rupture of membrane were higher in gestational diabetes mellitus as compared to overt diabetes among women. But in a study done by Mustary F et al and Abu-Heija AT et al shows higher incidence among overt diabetes as compared to GDM. ${ }^{18,19}$

Prematurity and low birth weight babies are more in overt diabetes as compared to gestational diabetes in present study. IUD rate was more in gestational diabetes as compared to overt diabetes in our study. This result is in contrast to the previous study by Mustary F et al which shows significant IUD in overt diabetes as compared to GDM. ${ }^{19}$ Epidemiological studies comparing diabetic and non-diabetic mothers have very clearly demonstrated adverse outcomes in diabetic mothers. Further, perinatal mortality and neonatal mortality rates are markedly higher among diabetic, compared to non-diabetic, pregnancies. $^{20}$

Pregnancy outcomes in diabetic women have improved dramatically over years with temporal trends showing a decline in rates of spontaneous abortions in diabetic mothers. However, diabetic mothers still carry a higher risk for fetal morbidity and mortality.

Gestational diabetes is a common yet serious disorder which in the majority of cases, should be managed efficiently. With good medical and obstetric care, the risks to the pregnancy should be minimal. However, a woman with GDM is a woman at high risk of future diabetes. Therefore, after the pregnancy, healthy lifestyle measures should be encouraged to minimize the likelihood of developing diabetes, and regular screening for diabetes should be undertaken.

\section{ACKNOWLEDGMENTS}

Authors would like to thank the patients and their relatives for supporting the study.

Funding: No funding sources Conflict of interest: None declared

Ethical approval: The study was approved by the Institutional Ethics Committee

\section{REFERENCES}

1. Metzger BE, Buchanan TA, Coustan DR, et al. Summary and recommendations of the Fifth International workshop-conference on gestational diabetes mellitus. Diabetes Care. 2007;30(Suppl 2):S251e60.

2. Anjana RM, Pradeepa R, Deepa M, Datta M, Sudha V, Unnikrishnan R, et al. Prevalence of diabetes and prediabetes (impaired fasting glucose and/or impaired glucose tolerance) in urban and rural India: Phase I results of the Indian Council of Medical Research-India Diabetes (ICMR-INDIAB) study. Diabetol. 2011;54:3022-7.

3. Kayal A, Mohan V, Malanda B, Anjana RM, Bhavadharini B, Mahalakshmi MM, et al. Women in India with gestational diabetes mellitus strategy (WINGS): methodology and development of model 
of care for gestational diabetes mellitus (WINGS 4). Indian J Endocrinol Metabol. 2016;20(5):707.

4. Keshavaraz M, Cheung NW, Babaee GR, Moghadam HK, Ajami ME, Shariati M. Gestational diabetes in Iran: incidence, risk factors and pregnancy outcomes. Diab Res Clin Pract. 2005;69:279.

5. Xiong X, Saunders LD, Wang FL, Demianczuk NN. Gestational diabetes mellitus: prevalence, risk factors, maternal and infants outcomes. Int J Gynecol Obstet. 2001;75:221.

6. Horvath K, Siebenhofer A, Koch K, Jeitler K, Matyas E, Bastian H, et al. Effects of treatment in women with gestational diabetes mellitus: systematic review and meta-analysis. BMJ. 2010;340:1-18.

7. Jacqueminet S, Jannot-Lamotte MF. Management of gestational diabetes. J Gynecol Obstet Biol Reprod (Paris). 2010;8S2:S251-S263.

8. Verier-Mine O. Outcomes in women with history of gestational diabetes mellitus. Screening and prevention of type 2 diabetes mellitus. J Gynecol Obstet Biol Reprod (Paris). 2010;8S2:S299-S321.

9. Buchanan TA, Xiang AH, Page KA. Gestational diabetes mellitus: risks and management during and after pregnancy. Nature Reviews Endocrinol. 2012;8(11):639.

10. Alfadhli EM. Gestational diabetes mellitus. Saudi Med J. 2015;36(4):399.

11. Coustan DR, Lowe LP, Metzger BE, Dyer AR. The Hyperglycemia and adverse pregnancy outcome (HAPO) study: paving the way for new diagnostic criteria for gestational diabetes mellitus. Am J Obstet Gynecol. 2010;202(6):654-e1.

12. HAPO Study Cooperative Research Group. Hyperglycemia and adverse pregnancy outcomes. New Eng J Med. 2008;358(19):1991-2002.

13. Mellitus GD. ACOG practice bulletin. 2018;190:4964.

14. Clausen TD, Mathiesen E, Ekbom P, Hellmuth E, Mandrup-Poulsen T, Damm P. Poor pregnancy outcome in women with type 2 diabetes. Diabetes Care. 2005;28(2):323-8.

15. Wahabi HA, Fayed A, Esmaeil SA. Maternal and perinatal outcomes of pregnancies complicated with pre-gestational and gestational diabetes mellitus in Saudi Arabia. J Diabetes Metab. 2014;5(399):2.

16. Jindal A. Prevalence, clinical profile and outcome of gestational diabetes mellitus. J Obstet Gynaecol. India. 2001;51:46-8.

17. Buckshee K, Rohatgi TB. Diabetes in pregnancy: current concepts. In: Saraiya UB, Rao KA, Chatterjee A, eds. Principles and practice of obstetrics and gynaecology for postgraduates $\left(2^{\text {nd }}\right.$ edition). New Delhi: FOGSI Publication. Jaypee Publishers; 2003:60.

18. Mustary F, Chowdhury TA, Begum F, Mahjabeen N. Maternal and perinatal outcome in gestational diabetes mellitus compared to pregestational diabetes mellitus. BIRDEM Med J. 2019;9(2):127-32.

19. Abu-Heija AT, Al-Bash M, Mathew M. Gestational and pregestational diabetes mellitus in Omani women: comparison of obstetric and perinatal outcomes. Sultan Qaboos University Med J. 2015;15(4):e496.

20. Shefali AK, Kavitha M, Deepa R, Mohan V. Pregnancy outcomes in pre-gestational and gestational diabetic women in comparison to nondiabetic women: a prospective study in Asian Indian mothers (CURES-35). The J Assoc Phys India. 2006;54(8):613-8.

Cite this article as: Banker CR, Mehta LR. Outcome of pregnancy in gestational diabetes as compared to overt diabetes. Int J Reprod Contracept Obstet Gynecol 2020;9:630-4. 